\title{
O PRINCÍPIO DA INIMPUTABILIDADE DA REDE E A REMOÇÃO DE CONTEÚDO DOS PROVEDORES DE APLICAÇÕES DA INTERNET
}

\author{
André Faustino* \\ Jorge Shiguemitsu Fujita**
}

SUMÁRIO:Introdução;20sprovedoresdeserviços deinternet; 3Ainimputabilidade da rede; 3.1 O Comitê gestor da internet - CGI e o decálogo da internet; 3.20 desenvolvimento do princípio da inimputabilidade da rede; 3.3 o princípio da inimputabilidade da rede; 4 A remoção de conteúdo dos provedores de aplicações de internet; 4.1 Os sistemas de remoção de conteúdo; 4.2 A oportunidade da remoção de conteúdo; 5 Considerações finais; Referências.

RESUMO: Este artigo analisa o princípio da inimputabilidade da rede, parte integrante do decálogo da internet do Brasil e a remoção de conteúdo dos provedores de aplicação de internet, prevista no Marco Civil da Internet, buscando compreender tais conceitos, estabelecendo a possibilidade de relação entre eles. Para tal finalidade, a pesquisa analisa os provedores de serviços de internet, o pensamento que influenciou a construção do conceito de inimputabilidade da rede e os sistemas existentes para a remoção de conteúdo de aplicações de internet existentes no Brasil, bem como a legislação americana e europeia que serve de base para esse instituto. $\mathrm{O}$ artigo conclui que é possível relacionar a inimputabilidade da rede com a remoção de conteúdo, pois o primeiro não significa isenção absoluta de responsabilidade, em que o segundo serve como medida de controle e correção de possíveis ilícitos praticados por terceiros dentro dos provedores de aplicação de internet.

PALAVRAS-CHAVE: Sociedade da informação; Marco civil da internet; Responsabilidade civil; Remoção de conteúdo.

\section{THE NON-ACCOUNTABILIT Y PRINCIPLE OF THE INTERNET AND THE REMOVAL OF CONTENTS BY INTERNET SERVERS}

ABSTRACT: The non-accountability of the Internet, an integral part of the Brazilian Internet Decalogue, and the removal of contents by servers, foreseen by the Internet

\footnotetext{
Advogado. Docente na Faculdades Metropolitanas Unidas (FMU). Mestrando do Programa de Mestrado em Direito da Sociedade da Informação Faculdades Metropolitanas Unidas (FMU), Brasil. E-mail: faustinoadv01@gmail.com

** Advogado. Doutor em Direito pela Faculdade de Direito da Universidade de São Paulo (USP). Docente do Programa de Mestrado em Direito da Sociedade da Informação e do curso de graduação em Direito Faculdades Metropolitanas Unidas (FMU), Brasil.
} 
Civil Mark, is analyzed. Concepts and their relationship are also discussed. Current research analyzes Internet servers, the idea that influenced the construction of the non-accountability concept and the existing systems for the removal of contents in Brazil, coupled to the US and European systems on which the Brazilian one was based. Results show that Internet non-accountability is related to content removal since the former does not mean absolute exemption of accountability; the latter is a means of control and correction of possible illicit practices by third party with the Internet server system.

KEY WORDS: Information society; Civil Mark of the Internet; Civil responsibility; Removal of contents.

\section{EL PRINCIPIO DE LA INIMPUTABILIDAD DE LA RED Y LA REMOCIÓN DE CONTENIDO DE LOS PROVEEDORES DE APLICACIONES DE LA INTERNET}

RESUMEN: En este artículo se analiza el principio de la inimputabilidad de la red, parte integrante del decálogo de la Internet de Brasil y la remoción de contenido de los proveedores de aplicación de Internet, prevista en el Marco Civil de la Internet, buscando comprender tales conceptos, estableciendo la posibilidad de relación entre ellos. Para tal finalidad, la investigación analiza los proveedores de servicios de Internet, el pensamiento que influenció la construcción del concepto de inimputabilidad de la red y los sistemas existentes para la remoción de contenido de aplicaciones de Internet existentes en Brasil, así como la legislación americana y europea que sirve de base para ese instituto. En este artículo se concluye que es posible relacionar la inimputabilidad de la red con la remoción de contenido, pues el primero no significa dispensa absoluta de responsabilidad, en que el segundo sirve como medida de control y corrección de posibles ilícitos practicados por terceros dentro de los proveedores de aplicación de Internet.

PALABRAS CLAVE: Sociedad de la información; Marco civil de la Internet; Responsabilidad civil; Remoción de contenido.

\section{INTRODUÇÃO}

Desde a popularização do acesso à rede mundial de computadores ou internet, a responsabilização civil dos usuários ou dos provedores de internet por atos praticados naquele ambiente produzem reflexos jurídicos; essa responsabilização é objeto de estudo constante e provoca o surgimento de uma série de correntes 
doutrinárias para explicar tais pontos. Dentro desse prisma, alguns conceitos emergem como, por exemplo, a responsabilidade dos provedores de aplicação de internet por conteúdo gerado por terceiros, remoção de conteúdo ofensivo, direito ao esquecimento ou direito à desindexação e a inimputabilidade da rede.

No Brasil, com o advento da lei 12.965/2014 que ficou conhecida como Marco Civil da Internet, alguns desses conceitos ficaram de certa forma mais evidentes e foram tutelados pelo Estado, trazendo um ponto de partida mais sólido ao se discutir questões relativas ao regramento jurídico que estabelece princípios e garantias para o uso da internet, bem como questões relacionadas à governança da internet, consequentemente propiciando um ambiente de segurança jurídica e de constante desenvolvimento na forma de enxergar o meio digital como uma via perene de relações e que faz parte do dia a dia dos indivíduos em sociedade.

Dentro do contexto da sociedade da informação as interações sociais passam a ser cada vez mais velozes e dotadas de fluidez e liquidez ${ }^{03}$, de certa forma, automatizadas na utilização da internet, mais especificamente na utilização das aplicações de internet ${ }^{04}$, pois basta apenas um comentário, um clique ou a publicação de uma imagem para que seja expressa a manifestação de uma opinião ou de um ponto de vista, porém essa instantaneidade tem outros lados, que são os da responsabilização e o da perpetuação daquela manifestação dentro da rede.

Dessa forma surgem desafios no sentido de como responsabilizar a própria rede, internet ou provedores por esses conteúdos gerados que podem ferir a privacidade, imagem e até direitos autorais de outras pessoas físicas ou jurídicas, bem como providenciar a remoção desses conteúdos que ferem tais direitos, de forma a garantir um ambiente de segurança jurídica e liberdade de expressão ao mesmo tempo.

O objetivo desse artigo é apresentar as principais possíveis influências do pensamento que origina o princípio da inimputabilidade da rede, constante no decálogo da internet do Brasil e as suas implicações na responsabilização civil dos provedores de internet, bem como a possibilidade da remoção de conteúdo da internet nos casos de solicitação por meio de ordem judicial ou até mesmo de pedido direto de uma pessoa que seja exposta ilicitamente por alguma publicação

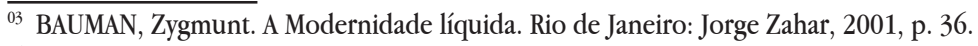

04 "Today's battle is not between David and Goliath; it's between David and David Letterman. While we thought the Internet might give us a generation of "digital renegades," it may have given us a generation of "digital captives," who know how to find comfort online, whatever the political realities of the physical world". (MOROZOV, Eugeny. Net delusion: the dark side of internet freedom. New York: Public Affairs, 2012, p. 70).
} 
ofensiva à sua imagem em casos envolvendo cenas de nudez ou de atos sexuais de caráter privado, buscando, ainda, verificar se existe correlação direta entre a inimputabilidade da rede - responsabilização civil dos provedores de internet e a remoção de conteúdo da internet, nos casos dos provedores de aplicação de internet, mais especificamente daqueles que possibilitam a publicação de imagens, comentários ou qualquer outra manifestação de opinião ou ponto de vista, quer seja ele em rede social ou não.

A metodologia utilizada neste trabalho parte do método dedutivo, realizando a revisão da bibliografia apontada nas referências, procurando visitar a doutrina, legislação e o que foi produzido sobre o tema apresentado. A leitura das obras apontadas nas referências foi a base do presente trabalho, em que a interpretação desses textos que serviram de subsídio para a construção do que será apresentado.

\section{OS PROVEDORES DE SERVIÇOS DE INTERNET}

O Marco Civil da Internet (MCI) em seu artigo $5^{\circ}$ nos incisos $\mathrm{V}$ e VII ${ }^{05}$ explicita o conceito de provedor de conexão de internet e provedor de aplicações de internet, respectivamente, embora o legislador não tenha inserido nos dois conceitos o nome provedor, a correta exegese do texto legal impõe a inserção do referido termo, portanto criando duas categorias de provedores de serviços de internet, o de conexão e o de aplicações de internet, ele procurou concentrar nesses dois conceitos todas as espécies de provedores de serviços de internet que possam existir, embora existam outras classificações, a opção foi por centralizar nesses dois tipos.

Em linhas gerais, o termo provedor de serviços de internet pode ser considerado gênero do qual outra categoria de provedores faz parte como, por exemplo, provedor de acesso, provedor de backbone, sendo que esses são espécie, portanto o provedor de serviços de internet nada mais é que a pessoa jurídica que oferece os serviços relacionados, de forma habitual, ao funcionamento da internet e

\footnotetext{
05 Art. 5o Para os efeitos desta lei, considera-se:

v - conexão à internet: a habilitação de um terminal para envio e recebimento de pacotes de dados pela internet, mediante a atribuição ou autenticação de um endereço IP;

VII - aplicações de internet: o conjunto de funcionalidades que podem ser acessadas por meio de um terminal conectado à internet;
} 
exploração de suas funcionalidades ou por meio dela. ${ }^{06}$

$\mathrm{O}$ provedor de conexão de internet é basicamente aquele que propicia o acesso do usuário a internet através dos provedores de conexão ou acesso, permitindo que ele possa navegar através da internet.

No início da popularização do uso da internet no Brasil, por volta do ano de 1995, era comum esse tipo de provedor oferecer os seus serviços através de um $\mathrm{CD}$ de acesso a internet com determinado prazo de validade. As empresas mais conhecidas naquela época eram a AOL (America Online) e a UOL (Universo Online), hoje existe uma infinidade de empresas que oferecem esse tipo de serviço e que, às vezes, parecem imperceptíveis para o usuário final.

Ainda em relação aos provedores de conexão de internet, existe uma série de serviços de outros tipos específicos de provedores, dentre os quais se destacam o provedor de backbone ${ }^{07}$ ou de estrutura, embora esse não seja mencionado no MCI, está ligado às questões de infraestrutura da internet, são aqueles provedores responsáveis por constituir a espinba dorsal da rede, são invisíveis aos olhos do usuário final da internet, porém possuem grande importância nas questões de hierarquia estrutural da constituição da rede, bem como nas questões relacionadas ao funcionamento e armazenamento das informações que por lá circulam, por essa característica mais estrutural é que esse tipo de provedor terá ligação direta com o princípio da inimputabilidade da rede, pois de certa forma nada mais é que a própria exteriorização do que se entende por rede.

Por outro lado temos os provedores de aplicações de internet ${ }^{08}$ e nesse grupo insere-se a maioria das "funcionalidades" que a internet propicia aos seus usuários finais, externando-se através dos sites de notícia, redes sociais, provedores de correio eletrônico ou e-mail, dentre outros.

Esses provedores oferecem a parte mais visível e perceptível do acesso e utilização da internet por parte dos usuários finais, nesse ambiente, usualmente,

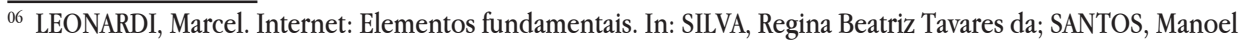
J. Pereira dos. Responsabilidade Civil na Internet e nos demais meios de comunicação. São Paulo: Saraiva, 2007 , p. 82.

${ }^{07}$ A internet é organizada na forma de espinhas dorsais backbones, que são estruturas de rede capazes de manipular grandes volumes de informações, constituídas basicamente por roteadores de tráfego interligados por circuito de alta velocidade. Disponível em: https:/www.cgi.br/legislacao/notas/nota-conjunta-mct-mcmaio-1995, acessado em 19 jun. 2017.

08 "O provedor de conteúdo é toda pessoa natural ou jurídica que disponibiliza na Internet as informações criadas ou desenvolvidas pelos provedores de informação, utilizando para armazená-las servidores próprios ou os serviços de um provedor de hospedagem". (LEONARDI. Marcel. Responsabilidade civil dos provedores de serviços de internet. São Paulo: Juarez de Oliveira. 2005. p. 27
} 
surge a maioria das possibilidades de lesão de direitos de terceiros por parte dos usuários, quer seja por crimes de calúnia e difamação, violação de privacidade ou lesão de direitos autorais, portanto sendo alvo constante das solicitações de remoção de conteúdo, bem como de ações que buscam a reparação de danos materiais e compensação de danos morais sob o argumento da responsabilização civil dos ofensores, bem como dos próprios provedores e é nesse ponto que esse tipo de provedor tem relação direta com a remoção de conteúdos de aplicações de internet.

\section{A INIMPUTABILIDADE DA REDE}

\subsection{O COMITÊ GESTOR DA INTERNET - CGI E O DECÁLOGO DA INTERNET}

Existe um órgão brasileiro denominado Comitê Gestor da Internet - CGI ${ }^{09}$ que foi criado no ano de 1995 possuindo caráter consultivo e que em linhas gerais tem a função de estabelecer diretrizes estratégicas gerais relacionadas ao uso e desenvolvimento da internet no Brasil, bem como conduzir estudos que busquem melhorar as questões relativas à governança da internet no Brasil, desenvolvendo um ambiente de inovação e atualização tecnológica, esse órgão foi criado pelo decreto $n^{0} 4.829 / 2003$.

O CGI realiza diversas reuniões ordinárias que tem como objetivo a deliberação de assuntos relacionados à governança da internet no Brasil, no ano de 2009 em uma dessas reuniões, por meio da resolução 003/2009 foram criados e estabelecidos dez princípios relativos à governança da internet no Brasil, que após a sua criação ficaram conhecidos como "O decálogo da internet", os princípios que lá foram definidos serviram de base para o entendimento de questões basilares relativas à internet como a liberdade de expressão, privacidade, proteção de direitos humanos etc.

Os princípios que compõem o decálogo da internet são a liberdade, a privacidade e os direitos humanos, a governança democrática e colaborativa, a universalidade, a diversidade, a inovação, a neutralidade da rede, a inimputabilidade da rede, a funcionalidade, a segurança e a estabilidade, a padronização e interoperabilidade, o ambiente legal e regulatório ${ }^{10}$.

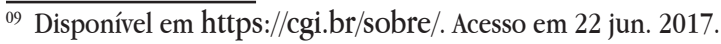

${ }^{10}$ Disponível em https://www.cgi.br/resolucoes/documento/2009/003. Acesso em 21 jun. 2017.
} 
Com a elaboração do decálogo da internet, o CGI criou a base para a discussão efetiva de questões relacionadas à governança da internet e foi o pano de fundo para o nascimento do projeto de lei 2.126/2011 que mais tarde deu origem ao marco civil da internet, portanto surtindo efeitos positivos dentro de um ambiente regulatório da internet no Brasil.

\subsection{O DESENVOLVIMENTO DO PRINCÍPIO DA INIMPUTABILIDADE DA REDE}

A internet popularizou-se em todo o mundo na década de 90 , com isso surgiram questões importantes sobre qual a forma de regular esse "novo mundo" denominado, naquele momento de ciberespaço ${ }^{11}$, de forma a permitir que as liberdades individuais fossem garantidas e respeitadas, porém por outro lado dentro de um ambiente de desenvolvimento e interações constantes, salvaguardando a possibilidade de responsabilização de possíveis ilícitos que viessem a ocorrer.

Dentro desse cenário surgiram alguns estudiosos da internet e até mesmo alguns entusiastas do tema, um dos primeiros a escrever sobre a regulação da internet foi John Perry Barlow que em seu texto "A Declaration of the Independence of Cyberspace ${ }^{12}$ ", uma espécie de reação a uma lei dos Estados Unidos de 1996 que buscava regular as telecomunicações naquele país e por consequência a internet; nesse texto Barlow procurou externar a possibilidade de que o ambiente da internet fosse um universo a parte e que por essa característica deveria ser isento de responsabilização, seria um lugar onde não haveria nenhuma lei ou possibilidade de regulação, sendo a sua visão bastante radical, até mesmo utópica, mas foi a expressão do que alguns estudiosos do tema naquele momento pensavam.

Vocês dizem que há problemas entre nós que vocês precisam resolver. Vocês usam este argumento como uma desculpa para invadir nossos recintos. Muitos desses problemas nem existem. Onde existirem verdadeiros conflitos, onde existirem verdadeiros erros, nós iremos identificá-los e resolvê-los da nossa própria maneira. Nós estamos formando o nosso próprio Contrato Social. Essa maneira de governar se

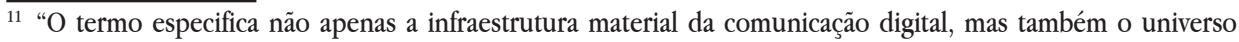
oceânico de informação que ela abriga, assim como os seres humanos que navegam e alimentam esse universo. Quanto ao neologismo 'cibercultura', especifica aqui o conjunto de técnicas (materiais e intelectuais), de práticas, de atitudes, de modos de pensamento e de valores que se desenvolvem juntamente com o crescimento do ciberespaço" (LÉVY, Pierre. Cibercultura. São Paulo: Editora 34. 1999, p. 17).

${ }^{12}$ Foi uma carta escrita por Barlow no Fórum Mundial de Davos no ano de 8 de fevereiro de 1996.
} 
estabelecerá segundo as condições do nosso mundo, não do de vocês. Nosso mundo é diferente. O Ciberespaço consiste de transações, relacionamentos e do próprio pensamento, como uma onda estacionária na nossa rede de comunicações. Nosso mundo está em todos os lugares e em lugar nenhum, mas não é no Ciberespaço que os corpos vivem. Nós estamos criando um mundo no qual todos podem entrar, sem privilégios ou preconceitos de raça, poder econômico, força militar ou local de nascimento.

O desenvolvimento desse conceito da ausência de regulação no ambiente da internet foi a possibilidade da criação de uma legislação mundial única que regulasse as questões relativas à internet, pois como o mundo da internet ou ciberespaço, era livre de fronteiras, uma lei única para o mundo todo seria suficiente para atender esse tipo de desafio que começava a surgir, pela natureza das relações que ocorriam no interior da internet, essa regulação única seria suficiente para atender todas as possíveis necessidades que surgissem dentro do ambiente "virtual"; seguindo essa linha de pensamento, David. R. Johnson e David G. Post escrevem o texto "Law and Borders - The Rise of Law in Cyberspace":

Muitos dos dilemas jurisdicionais e substantivos levantados pelas comunicações eletrônicas atravessando as fronteiras poderiam ser resolvidos por um princípio simples: conceber o ciberespaço como um "lugar" distinto para fins legais, analisando e reconhecendo uma fronteira legalmente significativa entre o Ciberespaço e o "mundo real". Usando essa nova abordagem não pedimos mais a pergunta irrespondível "onde" no mundo geográfico uma transação baseada em rede ocorreu. Em vez disso, as questões mais salientes tornam-se: quais os procedimentos mais adequados às características muitas vezes exclusivas deste novo lugar e as expectativas daqueles que estão envolvidos em várias atividades lá? Que mecanismos existem ou precisam ser desenvolvidos para determinar o conteúdo dessas regras e os mecanismos pelos quais eles podem ser forçados? As respostas a estas questões permitirão o desenvolvimento de regras mais adequadas aos novos fenômenos em questão, mais provável de ser feito por aqueles que entendem e participam desses fenômenos, e mais provável que sejam impostas por meios que os novos meios de comunicação globais disponibilizem e sejam efetivos ${ }^{13}$.

$\overline{13}$ GOLDSMITH, Jack.; WU, Tim. Law and Borders - The Rise of Law in Cyberspace: Estados Unidos: Stanford Law Review, 1996. p. 34. 
Após esse momento de mudança do pensamento da regulação universal da internet com uma lei única para regular o ciberespaço, começam a surgir estudiosos que desenvolvem o pensamento no sentido de uma regulação local da internet, ou seja, cada Estado deveria criar o seu ordenamento jurídico para estabelecer as normas específicas ou definir, como bem entender a forma de tutelar as relações ocorridas na internet, o que ocorre hoje em dia.

A maioria das avaliações sobre a globalização e, por consequência da internet, leva em conta que pela velocidade da informação e das constantes mudanças, ocorre a diminuição da relevância das fronteiras e de uma regulação local da internet, o que não corresponde a verdade, pois nesse contexto é que são necessárias normas para regular os diversos tipos de relações que surgem na internet ${ }^{14}$.

Por fim no ano de 1999, Lawrence Lessig, em sua obra Code and Other Laws of Cyberspace, propõe que a visão do ciberespaço como um lugar imune à regulação estatal e, portanto, um campo aberto para todas as liberdades, não está em todo adequada, pois na verdade não existe a dicotomia entre "mundo real" e "ciberespaço", na verdade são espaços únicos e não distintos, o que existem são grandes áreas que devem ser trabalhadas para buscar a regulação desse espaço, surgindo nesse contexto "o código" que seria algo mais importante, ele seria a lei, segundo o autor, ainda, propunha que deveria existir a interação entre lei, arquitetura, normas e mercado, para que houvesse uma regulação adequada considerando as questões legais e, também, questões ligadas ao aspecto técnico da rede.

Vivemos a vida no espaço real, sujeito aos efeitos do código. Nós vivemos vidas comuns, sujeitos aos efeitos do código. Vivemos vidas sociais e políticas, sujeitas aos efeitos do código. O código regula todos esses aspectos de nossas vidas, mais abrangentes ao longo do tempo do que qualquer outro regulador em nossa vida. Devemos permanecer passivos sobre essa regulação? Devemos deixar isso afetar-nos sem fazer nada em troca? ${ }^{15}$

Essas diversas formas de encarar a questão da regulação do espaço da internet ou a rede, bem como a evolução das relações entabuladas nesses espaços, influenciaram sobremaneira o modo de pensar em um desenho adequado para

\footnotetext{
${ }^{14}$ GOLDSMITH Jack; WU Tim. Who Controls the Internet? Illusions of a Borderless World. Estados Unidos: Oxford University Press, 2006. p. 56.

${ }^{15}$ LESSIG, Lawrence. Code and other laws of cyberspace. New York: Basic Books, 1999. p 28.
} 
elaboração de leis e princípios que atendessem essa realidade, um primeiro formato seria o de ausência de regulação, um segundo o de uma lei universal, o terceiro contemplaria legislações nacionais e o quarto ponto de vista, seria o da regulação local, porém levando em conta aspectos técnicos, como a arquitetura da rede, de forma que seria impossível somente pensar em um desenho legislativo que considerasse apenas o viés jurídico dissociado da realidade técnica desse ambiente, sendo que esse último ponto de vista foi o que prevaleceu e serviu de influência para a elaboração do decálogo da internet do Brasil.

\subsection{O PRINCÍPIO DA INIMPUTABILIDADE DA REDE}

Ao pensar no conceito da inimputabilidade da rede, deve se levar em conta primeiramente sobre qual instituto jurídico ele tem relação direita, sendo a resposta mais adequada à responsabilidade civil. O campo de observação desse princípio é relativo ao conteúdo gerado por terceiros dentro do ambiente fornecido pelos provedores de aplicação de internet, pois estes possuem a característica de permitir a interação dos usuários dentro do espaço oferecido, sendo que dentro desse campo é que surge a possibilidade de ocorrência de danos das mais diversas naturezas, em relação ao conteúdo gerado pelos próprios provedores ou por ato direito dos provedores, não resta dúvida que esses são os responsáveis por seus atos dentro de cada legislação aplicável in casu.

A inimputabilidade da rede ${ }^{16}$ pode ser definida, em breve comentário, como a exclusão da culpabilidade da rede, emprestando o conceito da inimputabilidade penal, não responsabilizando a rede, materializada por meio dos provedores de serviços de internet, por possíveis ilícitos ou abusos que venham ocorrer.

Com algumas exceções que o marco civil trata de forma a permitir um ambiente de liberdade de expressão no uso da internet, possuindo a característica de inovação e criatividade, mas responsabilizando o autor do ilícito, quer seja ele cível ou criminal, onde a rede funcionaria apenas como o meio oferecido para as interações.

\footnotetext{
$\overline{16}$ "A inimputabilidade da rede - ou a exclusão de culpabilidade - alude à delimitação das responsabilidades de diversos atores envolvidos na disponibilização e no uso da internet, com vistas a impedir a censura e promover a liberdade de expressão. De acordo com o Artigo 18 do Marco Civil, "o provedor de acesso à internet não será responsabilizado civilmente por danos decorrentes de conteúdo gerado por terceiros". Ou seja, companhias provedoras de conexão, de hospedagem de sites ou de search engines responderiam apenas em caso de desobediência de ordem judicial para exclusão de determinados conteúdos." (BEZERRA, Arthur Coelho.; WALTZ. Igor. Privacidade, Neutralidade e Inimputabilidade da internet no Brasil: Avanços e deficiências no projeto do Marco Civil. Revista Eptic Online Vol.16 n.2. 2014. p. 168).
} 
A lei 12.965/2014 distingue as figuras de responsabilização para os diferentes tipos de provedores de serviços de internet previstos, para os provedores de conexão de internet a inimputabilidade seria absoluta, não respondendo por conteúdo gerado por terceiros, já em relação aos provedores de aplicação de internet, a inimputabilidade é relativa, dependendo de qual tipo de relação esteja em análise, o que será visto em detalhe a seguir.

O marco civil da internet materializa esse princípio em sua seção III ao tratar da responsabilidade por danos decorrentes de conteúdo gerado por terceiros, preceituando em seu art. 18 que o provedor de conexão à internet não será responsabilizado civilmente por danos decorrentes de conteúdo gerado por terceiros, o legislador ao inserir esse artigo nessa seção levou em conta as características intrínsecas dos provedores de conexão à internet, pelo viés estrutural que esse tipo de provedor possui.

Conforme já dito no item 1 desse artigo, os provedores de conexão são aqueles ligados à estrutura da rede, dentre os quais se destacam os de backbone ou de acesso à internet, distinguindo-se ai dos provedores de aplicação de internet, pois o primeiro não possui a natureza de permissão aos usuários finais para interação dentro da sua plataforma, já que são, de certa forma, fechados para esse acesso de terceiros, sendo essa "abertura" a característica principal dos provedores de aplicações de internet.

Em relação à responsabilidade dos provedores de aplicação de internet por conteúdo gerado por terceiros o marco civil, também, busca tutelar as figuras da responsabilização civil dentro do princípio da inimputabilidade da rede, mais especificamente em seus artigos 19 e 21, porém com algumas imposições anteriores, que se não cumpridas por esse tipo de provedor, podem gerar a sua responsabilização, portanto nesse caso, podem ser responsabilizados por conteúdo gerado por terceiros caso não atendam o mandamento legal previsto para alguns casos, havendo uma espécie de mitigação do princípio da inimputabilidade da rede, que não pode ser considerado uma regra hermética e absoluta. Os referidos artigos tratam o assunto da seguinte forma:

Art. 19. Com o intuito de assegurar a liberdade de expressão e impedir a censura, o provedor de aplicações de internet somente poderá ser responsabilizado civilmente por danos decorrentes de conteúdo gerado por terceiros se, após ordem 
judicial específica, não tomar as providências para, no âmbito e nos limites técnicos do seu serviço e dentro do prazo assinalado, tornar indisponível o conteúdo apontado como infringente, ressalvadas as disposições legais em contrário.

$2^{\circ} \mathrm{A}$ aplicação do disposto neste artigo para infrações a direitos de autor ou a direitos conexos depende de previsão legal específica, que deverá respeitar a liberdade de expressão e demais garantias previstas no art. 5ํ-da Constituição Federal. Art. 21. O provedor de aplicações de internet que disponibilize conteúdo gerado por terceiros será responsabilizado subsidiariamente pela violação da intimidade decorrente da divulgação, sem autorização de seus participantes, de imagens, de vídeos ou de outros materiais contendo cenas de nudez ou de atos sexuais de caráter privado quando, após o recebimento de notificação pelo participante ou seu representante legal, deixar de promover, de forma diligente, no âmbito e nos limites técnicos do seu serviço, a indisponibilização desse conteúdo. Parágrafo único. A notificação prevista no caput deverá conter, sob pena de nulidade, elementos que permitam a identificação específica do material apontado como violador da intimidade do participante e a verificação da legitimidade para apresentação do pedido.

Em seu artigo 19, o marco civil da internet preceitua que somente após ordem judicial específica no sentido de tomar providências específicas para tornar o conteúdo infringente e se o provedor de aplicações de internet não tomar as devidas cautelas dentro dos limites técnicos, é que surge a possibilidade de responsabilização desse tipo de provedor por conteúdo gerado por terceiros, por óbvio essa cautela do legislador busca evitar que ocorram limitações à liberdade de expressão e outros direitos fundamentais que podem ser exercidos dentro do ambiente da internet, não deixando ao bel prazer dos usuários esse tipo de pedido, sendo reservada ao Poder Judiciário, após provocação dos usuários, a competência para avaliação dos pedidos e consequente determinação das devidas ações por parte dos provedores de aplicações de internet.

Existe, ainda, uma segunda regra de mitigação do princípio da inimputabilidade da rede, prevista no artigo 21 do marco civil da iInternet, sendo que esse mandamento legal visa preservar a dignidade da pessoa humana, intimidade, dentro outros direitos fundamentais, ao proteger a imagem das pessoas 
divulgadas sem sua autorização, contendo cenas de nudez ou de atos sexuais de caráter privado dentro do ambiente desses provedores de aplicação de internet, a responsabilidade dos provedores, nesse caso, é subsidiária e o pedido para tornar o conteúdo infringente indisponível é feito diretamente pela parte que foi exposta, não sendo necessária, nesse caso, a ordem judicial.

Tal previsão é bastante eficaz, principalmente, nos casos de pornografia de vingança ${ }^{17}$, evitando uma exposição desnecessária da parte que foi ofendida e gerando uma possível responsabilização do provedor de aplicação em caso de descumprimento da solicitação do ofendido.

Embora a denominação do princípio da inimputabilidade da rede possa parecer extremamente benéfica para os provedores de serviços de internet, sob a ótica da responsabilização dos atos gerados por terceiros dentro de seu ambiente, existem mecanismos legais que mitigam esse princípio, ajustando-o em um nível adequado sob o prisma da razoabilidade, pois permite que exista a responsabilização dos provedores nos casos previstos no marco civil da internet, permitindo que os usuários exerçam suas liberdades, sem deixar de lado o aspecto de tutela estatal e regulatória desse tipo de ambiente, levando em conta as características estruturais e de arquitetura da rede ou internet.

\section{A REMOÇÃO DE CONTEÚdo DOS PROVEDORES DE APLICAÇÕES DE INTERNET}

\subsection{OS SISTEMAS DE REMOÇÃO DE CONTEÚDO}

Existem dois tipos de sistemas de remoção de conteúdo dos provedores de aplicação de internet, o primeiro deles é o sistema conhecido como Notice and Takedowm (NAT) e o segundo sistema é por meio de determinação judicial. O sistema NAT é aquele em que a própria pessoa interessada na remoção do conteúdo

\footnotetext{
${ }^{17}$ Nonconsensual pornography involves the distribution of sexually graphic images of individuals without their consent. This includes images originally obtained without consent (e.g., hidden recordings or recordings of sexual assaults) as well as images originally obtained with consent, usually within the context of a private or confidential relationship (e.g., images consensually given to an intimate partner who later distributes them without consent, popularly referred to as "revenge porn"). Because the term "revenge porn" is used so frequently as shorthand for all forms of nonconsensual pornography, we will use it interchangeably with nonconsensual porn. (CITRON, Danielle Keats.; FRANKS, Mary Ane., Criminalizing revenge porn. University of Miami Law School. Institutional repository: 2014. p. 346).
} 
infringente faz o pedido diretamente ao provedor de aplicações e esse fazendo uma análise da pertinência e adequação, realiza a remoção do conteúdo solicitado, essa previsão é por meio de uma legislação existente ou por meio de precedentes judiciais que permitam tal possibilidade jurídica, já o sistema de determinação judicial é aquele em que a pessoa interessada tem que recorrer ao Poder Judiciário que, por ordem judicial específica, determina ao provedor de aplicações a remoção do conteúdo infringente.

Os pedidos de remoção de conteúdo, na maioria das vezes, é direcionado para os motores de busca, que recebem inúmeras solicitações para retirada de conteúdo infringente existentes; desde o ano de 2011 até fevereiro de 2017 o Google já recebeu mais de 2 bilhões de pedidos de remoção de conteúdo de suas páginas no mundo, os pedidos são, principalmente, aqueles ligados à lesão de direitos autorais ${ }^{18}$.

O ordenamento jurídico da União Europeia e dos Estados Unidos influenciou a forma de adoção de mecanismos para a remoção de conteúdo infringente nos casos de provedores de aplicações de internet no Brasil. Nos Estados Unidos existe um diploma legal denominado DMCA - Digital Milenium Copyright Act que autoriza a remoção de conteúdo por meio do $\mathrm{NAT}^{19}$, quando envolvidas questões que envolvem violações de direitos autorais e conexos, sendo que o referido diploma é atualmente bastante criticado por ter banalizado a sua utilização, figurando como uma espécie de censura nos Estados Unidos e existe, ainda, a seção 230 do CDA Comunication Decency Act - que é o nome de um título da Lei de Telecomunicações de $1996^{20}$ que prevê a inimputabilidade dos provedores de internet, porém em casos de descumprimento de alguns preceitos dessa lei pode surgir a responsabilização dos provedores, nos casos de edição de um conteúdo por parte do provedor e esse conteúdo é difamatório e ele passa a ser responsável, se o provedor passar a exercer atividades consideradas ilegais e, por fim, se o provedor prometer remover conteúdo

$\overline{18}$ Disponível em: https://olhardigital.com.br/noticia/google-recebe-mais-de-1-milhao-de-pedidos-de-remocaode-sites/66054. Acesso em 22 Jul. 2017.

19 "A doutrina norte-americana do notice and take down foi concebida para lidar especificamente com conflitos de natureza autoral. Em linhas gerais, a doutrina do notice and take down cria uma exceção à responsabilidade por violação de direitos autorais na internet, assegurando imunidade aos provedores de serviço (service providers) que atenderem prontamente à notificação do ofendido para a retirada do material impróprio. Com a notificação, o controvertido dever geral de monitoramento permanente da rede transforma-se em uma obrigação específica de agir, que, se atendida, isenta o provedor de responsabilidade" (SCHREIBER, Anderson. Novos paradigmas da responsabilidade civil: da erosão dos filtros de reparação à diluição dos danos. 5. ed. São Paulo: Atlas, 2013, p. 225).

${ }^{20}$ Essa lei de telecomunicações de 1996 foi a responsável por provocar a elaboração, por parte de John Perry Barloww, da Declaração da Independência do Cyberspaço. 
e não o fizer, ele passará a ser responsável.

$\mathrm{Na}$ União Europeia existem diversos diplomas legais que disciplinam o assunto, onde se destaca a diretiva 46/95/CE que disciplina o tratamento de dados pessoais, prevendo que a regra é a remoção de conteúdo por meiodo sistema de ordem judicial, porém em uma decisão no ano de 2014 em um caso envolvendo um homem chamado Mario Costeja González ${ }^{21}$ que buscava a remoção de conteúdo do motor de busca Google, com base no direito ao esquecimento ${ }^{22}$, o Tribunal de Justiça da União Europeia entendeu que existia a possibilidade de remoção de conteúdo e determinou a sua remoção, sendo que após essa decisão houve a abertura de precedentes para a remoção de conteúdo de provedores de aplicação de internet utilizando o sistema NAT.

$\mathrm{Na}$ legislação brasileira antes mesmo do surgimento do marco civil da internet, houve a promulgação de uma lei, a 12.034/2009, que alterou o Código Eleitoral e a Lei de Partidos Políticos, que previa em seu art. $57 \mathrm{~F}^{23}$ a possibilidade de remoção de conteúdo de provedores de internet mediante ordem judicial emanada da Justiça Eleitoral, inclusive com a responsabilização do provedor pela divulgação desse material em casos especificados na lei, mostrando já a possibilidade de remoção de conteúdo de provedores de aplicações de internet mediante ordem judicial.

O marco civil adotou dois sistemas de remoção de conteúdo em momentos distintos, a regra é a remoção por meio de ordem judicial específica, conforme o preceituado em seu artigo 19 e a segunda possibilidade é através do sistema NAT, nos casos que envolvam violação da intimidade com a divulgação de imagens, vídeos ou outro material contendo cenas de nudez ou atos sexuais de caráter privado, devendo o provedor de aplicações de internet remover o conteúdo infringente

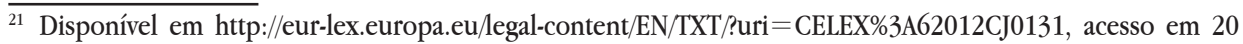
jun. 2017.

${ }^{22}$ Enunciado 531 da VI Jornada de Direito Civil - A tutela da dignidade da pessoa humana na sociedade da informação inclui o direito ao esquecimento. Artigo: 11 do Código Civil Justificativa: Os danos provocados pelas novas tecnologias de informação vêm-se acumulando nos dias atuais. O direito ao esquecimento tem sua origem histórica no campo das condenações criminais. Surge como parcela importante do direito do exdetento à ressocialização. Não atribui a ninguém o direito de apagar fatos ou reescrever a própria história, mas apenas assegura a possibilidade de discutir o uso que é dado aos fatos pretéritos, mais especificamente o modo e a finalidade com que são lembrados. Disponível em http://www.cjf.jus.br/enunciados/enunciado/142. Acesso em 21 jun. 2017

${ }^{23}$ Aplicam-se ao provedor de conteúdo e de serviços multimídia que hospeda a divulgação da propaganda eleitoral de candidato, de partido ou de coligação as penalidades previstas nesta Lei, se, no prazo determinado pela Justiça Eleitoral, contado a partir da notificação de decisão sobre a existência de propaganda irregular, não tomar providências para a cessação dessa divulgação. Parágrafo único. O provedor de conteúdo ou de serviços multimídia só será considerado responsável pela divulgação da propaganda se a publicação do material for comprovadamente de seu prévio conhecimento. Disponível em http://www.planalto.gov.br/ ccivil_03/_ato2007-2010/2009/lei/112034.htm. Acesso em 21 jun. 2017. 
após o pedido da parte ofendida, sendo que caso não seja acatada a solicitação o provedor passará a responder subsidiariamente junto com o ofensor, mostrando influência clara das exceções contidas na seção 230 do CDA.

\subsection{A OPORTUNIDADE DA REMOÇÃO DE CONTEÚDO}

A regra adotada no Brasil para remoção de conteúdo dos provedores de aplicações de internet nos casos de conteúdo infringente é por ordem judicial específica, em conformidade com o art. 19 do marco civil da internet, o que representa uma adequação da intenção do legislador às formas de relação que podem ocorrer na internet com algum equilíbrio.

A ordem judicial que determinar a remoção será devidamente fundamentada e observará os direitos envolvidos para assim prestar a tutela estatal no caso, evitando que essa forma de mecanismo funcione como meio de censura ou de cerceamento de direitos e liberdades individuais na internet ou de banalização de sua utilização.

A previsão de remoção de conteúdo por ordem judicial não significa que os provedores de aplicação de internet não possam promover a remoção voluntária de conteúdo de seus ambientes na internet, em casos pré-estabelecidos nos seus termos de uso e políticas de privacidade, informando como seria conduzida tal medida.

Um bom exemplo de caso envolvendo o pedido de remoção de conteúdo infringente por parte do usuário com base nos preceitos contidos no art. 21 do marco civil da internet (violação da intimidade), embora o caso tenha ocorrido antes da existência do referido diploma legal, já evidenciava como esses tipos de casos eram tratados pelo Poder Judiciário brasileiro. O caso em comento foi no ano de 2006 e envolvia a modelo Daniella Cicarelli ${ }^{24}$ e seu namorado à época, que foram filmados por um paparazzi em cenas íntimas em uma praia na Espanha, esse caso tomou notória repercussão, pois essas imagens foram divulgadas no youtube e expuseram a intimidade de ambos. O casal ajuizou uma ação em face do youtube solicitando como antecipação de tutela a remoção do conteúdo infringente com base na violação da privacidade e intimidade do casal, onde o pedido foi acolhido

\footnotetext{
${ }^{24}$ Disponível em http://g1.globo.com/Noticias/Tecnologia/0,,AA1412609-6174-363,00.html. Acesso em 24 Jul.
} 2017. 
à época com base no art. 461525, parágrafo $5^{\circ}$ do código de processo civil de 1973.

O risco em promover a remoção voluntária de conteúdo é que pode ocorrer a criação de um ambiente de restrição a liberdades individuais ou de censura prévia por parte dos provedores, o que representaria de certa forma, outra possibilidade de responsabilização desse mesmo provedor, pois a conduta, caso seja considerada abusiva, iria de encontro com valores basilares previstos na legislação que regula o uso da internet no Brasil, bem como a mandamentos constitucionais, como a liberdade de expressão e informação, insculpidas como cláusulas pétreas na Constituição Federal.

Existe, ainda, o risco de ao surgirem vários pedidos de remoção de conteúdo com base no artigo 19 do marco civil da internet - remoção por ordem judicial - ocorrer uma sobrecarga do Poder Judiciário, que terá que decidir sobre a pertinência e possibilidade de cada pedido feito, sendo que alguns pedidos não representam verdadeiros riscos para o autor do pleito, embora esse sistema seja o mais adequado para a mecânica de remoção de conteúdos na internet, pois transfere para um terceiro investido de poder e alheio a qualquer questão, a capacidade de decidir pela pertinência ou não da remoção.

Por outro lado a remoção de conteúdo por sistema NAT, previsto no artigo 21 do marco civil da internet, é mais evidente, pois envolve situações que podem ser verificadas de forma rápida e sem necessidade de um juízo de valor mais apurado, englobando aqueles casos que ferem imediatamente a dignidade da pessoa humana ao expor, sem autorização, a imagem de indivíduos em momentos de evidente intimidade, onde a demora em repelir esse tipo de agressão pode representar a ocorrência de danos permanentes ou de extrema dificuldade de reparação, inclusive com sérios riscos de perpetuação dentro do ambiente da internet, dependendo de sua extensão, o que não seria adequado e nem tolerável em um ambiente que preza pela regulação.

\footnotetext{
${ }^{25} \mathrm{Na}$ ação que tenha por objeto o cumprimento de obrigação de fazer ou não fazer, o juiz concederá a tutela específica da obrigação ou, se procedente o pedido, determinará providências que assegurem o resultado prático equivalente ao do adimplemento. $\S 5^{\circ}$ Para a efetivação da tutela específica ou para a obtenção do resultado prático equivalente, poderá o juiz, de ofício ou a requerimento, determinar as medidas necessárias, tais como a busca e apreensão, remoção de pessoas e coisas, desfazimento de obras, impedimento de atividade nociva, além de requisição de força policial.
} 


\section{CONSIDERAÇÕES FINAIS}

Embora possa parecer, em uma primeira análise, que o princípio da inimputabilidade da rede represente a irresponsabilidade civil total dos provedores de serviços de internet, fica claro que esse não é o objetivo, na verdade ele está intimamente ligado com o tipo de relação que os usuários da internet têm com a rede, pois o ambiente apresenta inúmeras possibilidades de interação e é um campo aberto para a expressão e manifestação de opiniões, para a exposição da vida particular, nos casos de redes sociais, por exemplo, e os provedores funcionam apenas como o espaço onde esse tipo de interação irá ocorrer.

Fica mais evidente essa questão nos casos dos provedores de conexão de internet, onde os usuários finais possuem pouco contato ou nos casos dos provedores de aplicações de internet, onde realmente ocorrem essas interações, sendo esse ambiente tutelado de forma mais efetiva pelo marco civil da internet, ocorrendo a mitigação do referido princípio.

Essa mitigação possui grande importância e terá ligação direta com os sistemas adotados para a remoção de conteúdo, que servirão como medida de controle da extensão do controle da inimputabilidade da rede, o sistema de remoção por ordem judicial representa a regra, já que está ligado com a maioria das possibilidades de danos que podem ocorrer no ambiente de internet e por características de uma indeterminação inicial da extensão desses danos, se mostra mais adequado que o Poder Judiciário realize a apreciação do pedido e após a análise da pertinência e possibilidade exare a ordem específica para a remoção do conteúdo infringente.

Por outro lado nos casos de remoção através do sistema Notice and Takedown a sistemática, também, parece bastante adequada já que ele irá incidir nos casos de exceção, especificados na lei, e que pelas suas características permitem que o próprio ofendido faça o pedido diretamente ao provedor de aplicações de internet que terá condições mínimas de fazer a análise e verificar a sua pertinência, sem contar que a demora em atendimento da solicitação, nesses casos, pode representar danos permanentes ou de difícil reparação para o ofendido.

Em relação à inimputabilidade da rede, existem conceituações técnicas a respeito da configuração estrutural dos tipos de provedores de serviços de internet existentes, pois eles representam a própria arquitetura da rede, o que pode ter relação direta com a dificuldade que, às vezes, o Judiciário tem em realizar a apreciação dos 
pedidos de remoção de conteúdo com base o art. 19 do marco civil da internet, mas que não exclui o caráter de responsabilização desses mesmos provedores caso não atendam as ordens de remoção, estando adequada a realidade de um Estado democrático de Direito. A remoção de conteúdo, nesse sentido, também terá ligação direita com o princípio da inimputabilidade da rede, pois é o instrumento que permite a parte ofendida por conteúdo infringente exercer o seu direito de pleitear que aquele mesmo conteúdo não fique exposto na internet e por lá se perpetue.

Dessa forma é possível harmonizar o princípio da inimputabilidade da rede com a possibilidade de remoção de conteúdo dos provedores de aplicações de internet, que nada mais são que a exteriorização da própria rede, pois a natureza das relações ocorridas na internet permite que aqueles que sejam ofendidos, por conteúdo infringente, tenham o direito de que ele seja removido, o provedor funciona como o espaço onde ocorrem essas interações, portanto parece adequado que a sua responsabilização deva ocorrer a partir do momento que ele possua ciência, quer seja por ordem judicial ou por pedido feito diretamente pelo ofendido, e não tome as devidas providências para que aquele conteúdo seja removido do seu espaço.

\section{REFERÊNCIAS}

BARLOW, John Perry. A declaration of the independence of cyberspace. 1996. Disponível em: http://www.dhnet.org.br/ciber/textos/barlow.htm. Acesso em: 21 jun. 2017.

BAUMAN, Zygmunt. A modernidade líquida. Rio de Janeiro: Jorge Zahar, 2001.

BEZERRA, Arthur Coelho; WALTZ, Igor. Privacidade, neutralidade e inimputabilidade da internet no Brasil: avanços e deficiências no projeto do Marco Civil. Revista Eptic Online, v.16, n. 2, 2014.

BRASIL. Lei no 5.869, de 11 de janeiro de 1973. Institui o Código de Processo Civil. Disponível em: <http://www.planalto.gov.br/ccivil_03/leis/L5869.htm>. Acesso em: 22 jun. 2017

BRASIL. Decreto $n^{0}$ 4.829, de 3 de setembro de 2003. Dispõe sobre a criação do Comitê Gestor da Internet no Brasil - CGIbr, sobre o modelo de governança da 
Internet no Brasil, e dá outras providências. Disponível em: < https://cgi.br/sobre/> . Acesso em 22 jun. 2017

BRASIL. Lei $\mathrm{n}^{\mathbf{0}} \mathbf{1 2 . 0 3 4}$, de 29 de setembro de 2009. Altera as Leis $\mathrm{n}^{\text {os }} 9.096$, de 19 de setembro de 1995 - Lei dos Partidos Políticos, 9.504, de 30 de setembro de 1997, que estabelece normas para as eleições, e 4.737, de 15 de julho de 1965 Código Eleitoral. Disponível em: < http://www.planalto.gov.br/ccivil_03/_ato20072010/2009/lei/12034.htm > . Acesso em: 20 jun. 2017.

BRASIL. Marco Civil da Internet. Lei 12.964/14. Disponível em: < http://www. planalto.gov.br/ccivil_03/_ato2011-2014/2014/lei/112965.htm>. Acesso em: 22 jun. 2017.

CITRON, Danielle Keats; FRANKS, Mary Ane. Criminalizing revenge porn. University of Miami Law School. Institutional repository: 2014.

DA SILVA, Beatriz Tavares; DOS SANTOS, Manoel J. Pereira. Responsabilidade civil: responsabilidade civil na internet e nos demais meios de comunicação. São Paulo: Saraiva, 2012.

GOLDSMITH Jack; WU Tim. Who Controls the Internet? Illusions of a Borderless World. Estados Unidos: Oxford University Press, 2006.

GOLDSMITH Jack; WU Tim. Law and Borders: The Rise of Law in Cyberspace: Estados Unidos: Stanford Law Review, 1996.

JORNADA DE DIREITO CIVIL, IV. Enunciado 531. Disponível em: < http://www.cjf. jus.br/enunciados/enunciado/142>. Acesso em 21 jun.2017.

LEONARDI, Marcel. Internet: Elementos fundamentais. In: SILVA, Regina Beatriz Tavares da; SANTOS, Manoel J. Pereira dos. Responsabilidade Civil na Internet e nos demais meios de comunicação. São Paulo: Saraiva, 2007.

LEONARDI, Marcel. Responsabilidade civil dos provedores de serviços de internet. São Paulo: Juarez de Oliveira, 2005.

LESSIG, Lawrence. Code and other laws of cyberspace. New York: Basic Books, 1999.

LÉVY, Pierre. Cibercultura. São Paulo: Editora 34. 1999.

MOROZOV, Eugeny. Net delusion: the dark side of internet freedom. New York: 
Public Affairs, 2012.

OLHAR DIGITAL. Google recebe mais de 1 milhão de pedidos de remoção de sites. Disponível em: < https://olhardigital.com.br/noticia/google-recebe-mais-de-1milhao-de-pedidos-de-remocao-de-sites/66054 > . Acesso em: 22 jul. 2017.

SCHREIBER, Anderson. Novos paradigmas da responsabilidade civil: da erosão dos filtros de reparação à diluição dos danos. 5. ed. São Paulo: Atlas, 2013.

UNIÃO EUROPÉIA. Tribunal de Justiça da União Européia (Grande Secção). Pedido de decisão prejudicial apresentado pela Audiência Nacional. Google Spain SL e Google Inc. vs Agência Espanhola de Protecção de Dados (AEPD) e Mario Costeja González. Disponível em: <http://eur-lex.europa.eu/legal-content/EN/ TXT/?uri=CELEX\%3A62012CJ0131> . Acesso em 20 jun. 2017.

Recebido em: 26 de junbo de 2017 Aceito em: 01 de novembro de 2017 